\title{
Comment And Opinion
}




\section{Comment and Opinion}

\section{Health Inequalities for Black and Minority Ethnic Groups in the UK: What has been done? \\ Dr Saima Latif, Research Fellow, University of Manchester}

Over the last twenty years, there has been a growing interest in the health of different communities in the UK as a result of ever increasing research evidence highlighting the disadvantaged health experiences of people from Black and Minority Ethnic (BME) Groups in the UK compared to the population overall. ${ }^{1,2}$ Differential disease patterns in health experiences for these groups particularly concern cardiovascular disease (CVD) diabetes, chronic kidney disease (CKD), cancer and mental illness, although there are many other areas which are also affected. However, there is more variation in the rates of the before mentioned diseases by ethnicity than by any other socio-economic factors. ${ }^{3}$ Nevertheless, socio-economics also play a significant factor in defining the differential statistics of inequality in health. ${ }^{4}$ Socio-economics include the poverty, the long-term impact of migration, racism and discrimination, poor delivery and take-up of health care, differences in culture and lifestyles and genetic susceptibility.

In the past 10 years, the Department of Health $(\mathrm{DH})$ have brought the agenda of health inequalities to the forefront with a number of high profile reports, in an attempt to increase the understanding of health inequalities and provide suggestions on how to reduce them amongst the UK population. These include The Acheson Report, ${ }^{5}$ The Darzi Report ${ }^{6}$ and even more recently The Marmot Report. ${ }^{7}$ These reports have been fundamental in highlighting inequalities in health in the UK and addressing ethnic inequalities. The more recent Marmot Report has been heavily criticised for paying little attention to the issue of ethnic inequalities in health.

These reports have been the foundation for a range of government initiatives to tackle health inequalities to include; Tackling inequalities in health: A programme for action, ${ }^{8}$ Health Survey for England, ${ }^{9}$ Race for Health, ${ }^{10}$ Spearhead Primary Care Trusts ${ }^{11}$ and Health Challenge England. ${ }^{12}$

This paper will comment on the extent these government reports and initiatives have been successful in tackling health inequalities, what has been done so far to reduce disparities and where the focus needs to be placed for further improvements.

What is the evidence for Health Inequalities?

There is evidence to show that health inequalities exist for BME groups with particular reference to $C V D$, diabetes, kidney disease and mental illness. These are further described below:

CVD

South Asian groups living in the UK have a higher prevalence of CVD conditions than the general population of England. However, there are also intra-ethnic differences with Pakistani and Bangladeshi men having rates of CVD that are $60 \%$ to $70 \%$ higher than men in the general population. The figures for women are similar, with Pakistani $(45 \%)$ and Bangladeshi $(43 \%)$ women having higher rates of CVD conditions than women in the general population. ${ }^{13}$

\section{Diabetes}

Type 2 diabetes is up to six times more common in people of South Asian descent and up to three times more common among people of African and Caribbean origin. According to the Health Survey 
for England, ${ }^{14}$ doctor-diagnosed diabetes is almost four times as prevalent in Bangladeshi men, and almost three times as prevalent in Pakistani and Indian men compared with men in the general population.

Amongst women, diabetes is more than five times higher amongst Pakistani women, at least three times higher in Bangladeshi and Black Caribbean women, and two and a half times higher in Indian women, compared with women in the general population.

CKD

A further complication of diabetes is CKD, a major cause of end-stage renal failure (ESRF). In England, $4.2 \%$ of the South Asian community and $3.7 \%$ of those from African-Caribbean backgrounds ${ }^{15}$ were reported to have CKD. Furthermore, UK data shows that South Asian people with diabetes are up to ten times more at risk of developing ESRF compared to the white population ${ }^{16}$. Thus, not only are South Asian people and African-Caribbean people more prone to diabetes than white British people, they are more likely to develop ESRF as a consequence.

\section{Mental Illness}

Ethnic differences in mental health are controversial. Most of the research surrounding ethnic mental health is based on treatment rates, which show that BME people are much more likely to receive a diagnosis of mental illness than White British people. ${ }^{17}$ Research studies have shown that new diagnosis of psychosis among Black Caribbean people are up to seven times higher than among the White British. ${ }^{18}$ There is evidence of ethnic differences in risk factors that operate before a patient comes into contact with the health services, such as discrimination, social exclusion and urban living. Research has also shown that psychiatrists diagnose potential symptoms of mental illness differently depending on the ethnicity of the patient. ${ }^{19}$

\section{Health Inequalities Policies}

Sir Donald Acheson's Independent Inquiry into Inequalities in Health ${ }^{20}$ was a key initiative for putting the health inequalities onto the policy agenda. This report placed a strong emphasis on the effects of wider inequalities, poverty and social exclusion on health inequalities.

The Acheson Inquiry made three recommendations for reducing health inequalities. This report recommended that policies should reduce socio-economic inequalities and consider the needs of BME groups, services should be sensitive to the needs of BME groups and promote awareness to their health risks and the needs of BME groups should be specifically considered in planning and providing health care.

Up until this report came into the public arena, ethnicity had not been a focus of health inequalities policies to date. This report is a critical reference point in the health inequalities debate and a turning point for reform and action.

Lord Darzi's final review, High Quality Care for All ${ }^{21}$ was another significant milestone in the Health inequality and policy arena. In this review, Lord Darzi drew out four overarching themes for the NHS in a ten year plan. He described the vision of a health care system that is fair, personalised, effective and safe with world class commissioning central to achieving the vision. Darzi's wish was to remedy health inequalities and make services more accessible for ethnic minorities was greatly welcomed by all.

Further on from this, the more recent high profile Marmotreport, ${ }^{22}$ another addition to the government's more recent efforts to tackle the persistent problem of health inequalities has been something of 
an anti-climax. In an attempt to focus on redressing deep-rooted socioeconomic inequalities it has paid little attention to ethnic inequality. Whilst the report includes passing reference to the social and health disadvantage experienced by particular ethnic groups in a number of places, it fails to give any meaningful attention to this key dimension of identity and division of modern British society.

The Marmot review fails to highlight the systemic factors that persistently reproduce inequitable experiences and outcomes in healthcare for BME groups, including: poor patient-provider communication; a failure of programmes to address issues of most concern to minority people; a lack of visible BME presence among staff; discriminatory attitudes and behaviour by staff; feelings of exclusion and mistrust by BME groups; a lack of cultural sensitivity in provision of services and a lack of funding and resources.

In order to remedy health inequalities, there are two intersecting factors which need to be addressed; the availability of data on ethnicity and the legal obligations towards racial equality.

\section{Ethnicity Data}

The availability of ethnicity data is pertinent if we are to address health inequalities effectively. Large-scale surveys are currently the most useful source of data on ethnic health. The Health Survey for England measures ethnic health inequalities every five years. Unfortunately, as ethnicity is not recorded at death, an individual's mortality can only be estimated by their country of birth. There is also a lack of regular and accurate data to monitor ethnic variation in the use of NHS services. Currently the collection of ethnicity data is only mandatory in secondary care. The DH's Quality of Outcome Framework introduced a small financial incentive to GP practices that have complete ethnicity data on their patient profiles. Nevertheless, patchy ethnicity data in primary care undermines planning and evaluation of policy and precludes the monitoring of changes over time. The Commission for Racial Equality (CRE) has recommended that the DH moves forward more quickly with ethnic monitoring. The proposed electronic patient record in secondary care should make this somewhat easier. In addition, the Audit Commission has highlighted the need to understand better how evidence can be used to bring about change in racial equality. The London Health Observatory has produced a tool to guide NHS bodies in using ethnic data for health impact assessment. ${ }^{23}$

\section{Legal Obligations}

Under the Race Relations Amendment Act, $2000^{24}$ public organisations have a legal obligation to stop racial discrimination and promote equal opportunities by; producing a Racial Equality Scheme; performing Race Equality Impact Assessment on all policies and monitoring outcomes by each ethnic grouping. However, a King's Fund review of 300 Primary Care Trusts (PCTs) in 2007 found that a third did not comply with the Act. ${ }^{25}$ Unless all organisations take the role of race relations seriously, and try to eliminate racism, the drive for equality in health care will remain even more difficult to achieve.

Since the Acheson report and related policy recommendations, a number of government initiatives have been introduced in an attempt to reduce inequalities in the UK society. These have mainly targeted health care and NHS funding. Besides issues of poor health provision in deprived areas, policies have explicitly focused on achieving equity for different BME groups. The main approach has been to identify good practice in racial equality and to mainstream these strategies throughout the NHS.

\section{Delivering Equity in Health Care for BME Groups}

The government's commitments to improving health service use by BME groups are laid out in the DH's Race Equality Scheme 2005-2008 ${ }^{26}$ which sets out specific goals. The majority of change in ethnic health inequalities is taking place in mental health services.

\section{Good Practice}


The DH has commissioned a number of initiatives to generate or collate good practice in race equality, such as Pacesetters ${ }^{27}$ Race for Health ${ }^{28}$ and the NHS Specialist Library for Ethnicity and Health, ${ }^{29}$ tackling problems such as barriers to access, language and cultural competence. However, this is something of a 'Catch 22' situation for the lack of baseline data on ethnicity makes it difficult to evaluate the impact of these projects, which in turn makes it hard to identify good practice.

\section{Redirecting Funds}

In 2002, the DH decided to redirect funds towards areas with larger BME populations and deprived groups whose needs were not being met. This has helped to fund activities in the Spearhead Areas,30 more specifically BME interpreting and translation services.

\section{Reducing Poverty and Social Exclusion}

Initiatives aiming to reduce poverty and social exclusion have the potential to tackle the root causes of health inequalities. However, a Social Exclusion Unit review of initiatives has questioned whether BME groups have benefited from the drive to reduce social exclusion. Rather than explicitly targeting BME groups, policies tend to assume that BME groups will benefit by virtue of their relative poverty and concentration in deprived areas.

\section{Financial Poverty}

Financial poverty is one factor that persistently helps to widen the health inequality gap in society. Several policies have aimed at reducing income poverty in recent years, through benefits levels, tax credits, and welfare to work programmes. However, there has been little ethnic targeting of welfare policies to date, despite persistently high levels of poverty in some BME groups. ${ }^{31}$

\section{Interventions in Life}

The targets on child poverty and initiatives like Sure Start aim to improve child development, to prevent the continuation of social deprivation and vulnerability to ill health between generations. However, despite high levels of child poverty in some BME groups, there has been no ethnic targeting in the policies to redress child poverty. For instance, the Joseph Rowntree Foundation has recommended changes to benefits and tax credits, which still favour small families above the larger families which are mostly represented by BME groups. ${ }^{32}$

\section{Area-based Initiatives}

Health Action Zones, Neighbourhood Renewal, the New Deal for Communities, Sure Start, and most recently, the Spearhead Area initiatives are all aimed at reducing health inequalities and social exclusion by targeting deprived areas. They involve partnerships between PCTs, local authorities, voluntary sector organisations and industry. Although they may have benefits for health, evaluating the impact of area-based initiatives is difficult. The initiatives focus on areas which often have high BME populations. However, the lack of ethnic monitoring means it is not possible to examine BME involvement in the activities, or examine outcomes by ethnic group.

\section{Conclusion}

This paper discusses the main areas of health inequalities that persist for BME groups in the UK, the governmental policy documents that have aimed to increase awareness of health disparities and the government initiatives that have been brought out to address health inequalities in practice.

Health inequalities do exist for minority ethnic groups, and there is a complexity of underlying reasons. BME groups generally have worse health than the overall population, although the patterns of ethnic health inequalities are very diverse. Ethnic health inequalities result from many interlinking factors. Policy responses cover a wide spectrum and incorporate initiatives to improve the use of health services by BME groups, as well as tackling broader socioeconomic inequalities between ethnic groups. The current system reforms in the NHS should offer the opportunity to develop services 
specific to local communities' needs. ${ }^{33}$ Alongside the system reform agenda is the introduction of the DH's Race Equality Scheme which clearly places an obligation on NHS organisations to 'do more to deliver services which meet the particular needs of black and minority ethnic groups.' ${ }^{34}$

However, the most important activity in achieving any of this is to ensure robust data collection of ethnic monitoring statistics. Unfortunately, the lack of ethnic monitoring being statutory within primary or secondary care represents a serious flaw in developing health care services to address health disparities amongst BME groups. It remains to be seen, however, whether the introduction of the QOF and any similar schemes will encourage such practices.

It is possible, via Local Strategic Partnerships and utilising current NHS system reform, to improve the health of minority ethnic groups. There remains an urgent need to improve data collection relating to ethnic monitoring so that the reality and the scale of the challenge in reducing health inequalities is better understood.

\section{References}

1. Nazroo, J, Y. Mental Health and Ethnicity: Findings from a National Community Survey. London: Policy Studies Institute, 1997.

2. Sproston, K. and Mindell, J. Health Survey for England 2004. Volume 1: The Health of Minority Ethnic Groups. London: The Information Centre, 2006.

3. Bhopal, R. Ethnicity, Race and Health in Multicultural Societies: Foundations for Better Epidemiology, Public Health, and Health Care. Oxford: Oxford University Press, 2007.

4. Nazroo, J. The Structuring of Ethnic Inequalities in Health: Economic Position, Racial Discrimination and Racism, American Journal of Public Health, 93(2), 2003, 277-284.

5. Acheson, D. Independent Inquiry into Inequalities in Health - Report. London: The Stationery Office, 1998.

6. Darzi, A. High Quality Care for All: NHS Next Stage Review Final Report. London: The Stationery Office, 2008.

7. Marmot, M. Fair Society, Healthy Lives. London: The Marmot Review, 2010.

8. Department of Health, Tackling Health Inequalities: Cross Cutting Review, London: The Stationery Office, 2002.

9. Sproston and Mindell (ref. 2).

10. Department of Health. Race for Health [Online]. 2007. (Retrieved March 16, 2010), (Url http:// www. raceforhealth.org).

11. Department of Health, Reid Announces 'Spearhead' PCTs to Tackle Health Inequalities. Press release 19 November 2004.

12. Department of Health, Our Health, Our Care, Our Say: A New Direction for Community Services. London: The Stationery Office, 2006.

13. Erens, B. Primatesta, P. and Prior, P. Health Survey for England: The Health of Minority Ethnic Groups '99. London: The Stationery Office, 2001.

14. Sproston and Mindell (ref. 2). 
15. Department of Health, National Service Framework for Renal Services. London: The Stationery Office, 2004.

16. Lightstone, L. Preventing Kidney Disease: The Ethnic Challenge. Peterborough: National Kidney Research Fund, 2001.

17. Dutt, R. and Ferns, P. 'Letting through the light'- A Training Pack on Black People and Mental Health. London: Department of Health, 1998.

18. Cochrane, R. Sashideran, S. Mental Health and Ethnic Minorities: a Review of the Literature and Implications for Services. Birmingham: School of psychology, Birmingham University, not dated.

19. Bhugra, D. and Bhui, K. African-Caribbeans and Schizophrenia: Contributing Factors. Advances in Psychiatric Treatment, 7, 2001, pp. 283-291.

20. Acheson (ref. 5).

21. Darzi (ref. 6).

22 Marmot (ref. 7).

23. London Health Observatory, [Online]. (Retrieved March 23, 2010). (Url http://www.Iho.org.uk/Training/ HIA/AboutHIA.aspx (2003).

24. Office of Public Sector Information, Race Relations (Amendment) Act 2000. [Online]. 2000. (Retrieved April 20, 2010). (Url http://www.opsi.gov.uk/acts/acts2000/ukpga_20000034_en_1. )

25. The King's Fund Information and Library Service, Ethnic Health- An Introduction to Ethnic Health Issues. [Online] 2009. (Retrieved April 18, 2010). (Url http://www.kingsfund.org.uk/resources/information_and_ library_service/readinglists)

26. Department of Health. Race Equality Scheme 2005-2008. London: The Stationery Office, 2005.

27. The National Centre for Involvement, Pacesetters programme Community Engagement guidance.

[Online] 2008. (Retrieved April 17, 2010). (Url

http://www.nhscentreforinvolvement.nhs.uk/index.cfm?action=PRE\&PressID=49)

28. NHS Evidence, Ethnicity and Health [Online]

2010. (Retrieved April 18, 2010) (Url http://www.library.nhs.uk/ethnicity/)

29. Policy Studies Institute, Poverty at root of ethnic equalities in health. [Online] 1997. (Retrieved April 13, 2010) (Url http://www.psi.org.uk/news/pressrelease.asp?news_item_id=61 (1997)

30. Department of Health (ref. 11).

31. Chzhen, Y. and Middleton, S. The Impact of Tax Credits on Mothers' Employment. York: Joseph Rowntree Foundation, 2007.

32. Chzhen and Middleton (ref. 31).

33. Department of Health (ref. 12).

34. Race for Health (ref. 10). 


\section{The Illinois Documentary History of Black Studies: Toward a new approach to the history of Black Studies}

http://www.ideals.illinois.edu/handle/2142/14912

Abdul Alkalimat

The history of Black Studies in the US has been on the research agenda ever since Black Studies became the most important result of the Black Power Movement. However, the history of Black Studies has been captured by a two part narrative, socially constructed by the national media around high profile, elite schools on both coasts. Part one is that a nationalist struggle emerged to create a Black Power initiative within educational institutions. Part two is that the nationalists were failing and the situation had to be rescued by an academic postmodern elite. This polarity is the usual dialectic imposed on Black history: nationalism versus integrationism. It has been socially constructed and defended, with limited empirical investigation. But it is an oversimplification of a very courageous process that took place in every setting of higher education in the United States. It negates the diversity of Black Studies. It silences a great deal of talent. And we are now developing a tool for solving this problem, the Illinois Documentary History of Black Studies (http://www.ideals.illinois. edu/handle/2142/14912), and we invite you to join us.

\section{Black Studies starts to study itself}

Recent Black Studies scholarship has demonstrated the utility of case studies, for instance Bradley (2009) on Columbia University; comparative studies, such as Rojas (2007)on University of Chicago and University of Illinois at Chicago and Small (1999) on Harvard and Temple; and discipline-wide datasets such as Alkalimat (2006, 2007, 2007). We know a lot, but we do not have a sufficiently large enough sample of detailed case studies to firmly anchor this field of study in the kind of data required to sustain serious scholarship.

Part of our problem is that we have fallen victim to edutainment by the public intellectuals who launch from the elite bastions of higher education. Many have been led to believe that what these high profile individuals think about what happened in the history of Black Studies is more important than the facts of what happened in more than 500 institutions of higher education. So our focus today is on how to re-value the actual founders of Black Studies, campus by campus-the wise community elders and the campus warriors, intellectuals and diplomats among faculty and students. In order to liberate this history and construct a resource or tool that many others can use to do so, we go into the libraries and archives, we return to the source.

\section{Constructing a tool for the broad study of the history and sociology of our own field}

In these times, when one thinks of a project one then thinks of where the funding is going to come from. In returning to the source we also have to reinvent how to do things, how to get things done without a grant, without asking for permission. So our overall strategy is to turn the classroom from a site of intellectual consumption to a site of production. Thousands of hours of student labor can be used productively. Carrying out actual research is in fact a better pedagogical approach than aiming for the passive acceptance of existing knowledge.

We started this process at the University of Illinois, anticipating having our proposal approved for a new PhD degree program in Black Studies to launch in 2012. Our first results come from a small graduate seminar in Fall 2009 where four students produced four documentary case studies of the history of Black Studies:

1. Northwestern University

2. University of Illinois at Springfield

3. South Suburban Community College

4. Loyola University 
For all four students this was an engaging, practical and realistic course project that woke them up to Black Studies and to scholarship generally. They also got published! Everyone liked seeing their name in print.

\section{Research methods}

Each student's goal was to reproduce the basic documents that contain the empirical data needed to study the history of the academic program at the school they selected. In each instance, the student began by downloading and printing the existing web site of the program. Next, he or she examined the library website for information on campus archives. Following this the next stop was the media, on and off campus, to see what was available online and what might be found in hard copy archives. The goal was to gather as much as possible before making contact with people on campus and alumni, so that the students would be looking for specific information and not merely staying in the realm of the general.

We planned full day campus trips, mainly to photocopy material since the focus was to gather primary documents. Key to this were the current unit head (director or chair), the departmental secretary, the key archivist or Black Studies librarian, and any officials on campus with a past history connected to the program. The use of email was essential in making contact with people in advance, and giving people ample time to respond was critical as well.

When on campus collecting data, the first task was to copy the official college catalog material concerning Black Studies, covering the 1960 s to the present. This is self-reported information by the campus, and is their official legal document. Next stop was the campus archives to find and copy the official documents of the founding of the program and all possible written communications: early demands and the official campus response from the faculty, administration, and board of trustees; course syllabi, all possible written communications. This gave key dates that could be used to search media archives for local reporting on and off campus. This process enabled us to get a list of the key actors in the origin and subsequent leadership of the program. Finding contact information and soliciting help also proved to be useful as people were friendly and contributed information and material to the projects.

\section{Research results}

Once all of the material was sorted and organized into sections of a volume, with an introduction and other explanatory material, we photocopied it and simultaneously created a PDF file. This became a limited edition of a printed and bound volume and a digital ebook at the same time. Three official hard copies were produced, one for the school in question, one for the Vivian G. Harsh Research Collection of Afro-American History and Literature at Chicago Public Library, and one to the reference collection of the African American Research Center (AARC) of the History, Philosophy \& Newspaper Library. The ebook is permanently available at IDEALS, a free and public digital repository such as many research universities are now building:

IDEALS collects, disseminates, and provides persistent and reliable access to the research and scholarship of faculty, staff, and students at the University of Illinois at Urbana-Champaign. Faculty, staff, and graduate students can deposit their research and scholarship - unpublished and, in many cases, published - directly into IDEALS. Departments can use IDEALS to distribute their working papers, technical reports, or other research material. (http://www.ideals.illinois.edu/)

By using IDEALS as well as sharing hard copy with several institutions, these four volumes containing the campus-by-campus historical documentation of the history of Black Studies will be permanently available for research. 


\section{Next steps: Calling all scholars and students}

We invite everyone to start to use these four volumes, since they are available locally and globally via the internet. But we are making a broader call because these four volumes are but a start, in four important ways:

1. Working together, we can assemble more documents from the four campuses where we began. Each program has had at least three generations of leadership and faculty and many syllabi and publications, so each campus deserves multiple volumes.

2. Working together, we can document many more Black Studies programs in the US and produce additional volumes. The formula we have worked out in this first go was a success, and we are sharing it here. Choose a campus, use our approach, get in touch with us, and your hard copy and online volume will materialize. Partners have already stepped forward from California, Georgia, New York, and elsewhere in Illinois.

3. We are also interested in documenting Black Studies programs outside the US-in Europe and the UK, Latin America and the Caribbean, Asia and Africa-that were inspired by the US Black Power movement.

4. The volumes are primary documents, our level 1 data, the raw stuff. One way to start using them is to produce level 2 data, which would include a coded database that shrinks things down into manageable information. Quantitative and factual information (e.g., names, dates, numbers, specific decisions, etc.) can be easily coded and placed in a commonly used database structure for general use. Qualitative analysis will require experimenting with computer assisted tools in order to have a tool to accompany the data that can be used by researchers at all levels. That level 2 data can be published as well, in hard copy and on IDEALS, with full authorship.

What we are seeing is that each volume immediately becomes required reading for people currently building each academic program. They will likely be among the first users and their use will make the Documentary History of Black Studies more valuable to everyone. Any weaknesses they find will guide future work. Alumni and former faculty are also taking notice and making their contributions as well.

If you are interested in creating or using a volume or contributing in any way, please get in touch. 